\title{
Obesity and the onset of depressive symptoms among middle-aged and older adults in China: evidence from the CHARLS
}

\author{
Huiqiang Luo', Jijie Li ${ }^{2}$, Qi Zhang ${ }^{1}$, Peiya Cao ${ }^{3}$, Xiaohui Ren ${ }^{4 *}$, Aiping Fang ${ }^{1}$, Haiying Liao ${ }^{1}$ and Lijuan Liu
}

\begin{abstract}
Background: The association between obesity and depression has been documented in previous systematic studies but remains controversial. Many prospective studies have focused on children and youth, and several studies have examined this relationship among older populations. This study of the changes in obesity status aimed to examine the association between depression and obesity among middle-aged and elderly adults in China.

Methods: The data originated from the follow-up survey (2011 and 2013-2015) of the China Health and Retirement Longitudinal Study (CHARLS) and included 3337 residents aged at least 45 years who completed a physical examination and were evaluated with the Center for Epidemiological Studies Depression Scale (CES-D-10), which assessed depressive symptoms. Obesity status was defined by body mass index (BMI) and waist circumference (WC) according to Chinese criteria. A time-dependent Cox proportional hazards model was used to estimate the relationship between obesity status and depressive symptoms.
\end{abstract}

Results: The rate of depression in men and women was 26.67 and 38.37\%, respectively. Based on BMI, the proportion of the population that was overweight and obese was 28.07 and 9.26\%, respectively, in males and 35.03 and 16.84\%, respectively, in females. Males with obesity were less likely to suffer from depressive symptoms than males with a normal weight $(\mathrm{ORHR}=0.506,95 \% \mathrm{Cl}=0.347 \sim 0.736)$. Based on $\mathrm{WC}$, the proportion of abdominal obesity was $49.35 \%$ in males and $73.65 \%$ in females. Males with abdominal obesity were less likely to suffer from depressive symptoms than males without abdominal obesity (ORHR $=0.775,95 \% \mathrm{Cl}=0.644 \sim 0.933)$.

Conclusion: Obesity is more likely to be associated with the onset of depression in males than in females. However, regardless of underweight or overweight status, the relationship between weight and depressive symptoms is negatively associated among females and males. In conclusion, both BMI and WC can be used as tools for examining the association between obesity and depression.

Keywords: Obesity, Depression, Chinese, Middle-age and older adults, CHARLS

\section{Background}

According to the World Health Organization, the prevalence of worldwide obesity has undergone a significant change since 1980 [1]. In the US, the prevalence of obesity accounts for one-third of the general population, and another one-third is overweight [2]. Similarly, the level and trend of obesity rates have also become a major public

\footnotetext{
*Correspondence: renxiaohui@scu.edu.cn

${ }^{4}$ Department of Health Related Social and Behavioral Science, West China School of Public Health (No. 4 West China Teaching Hospital), Sichuan University, No. 17 Section 3, Renmin South Road, Chengdu 610041, Sichuan, China

Full list of author information is available at the end of the article
}

health concern in China [3]. Obesity is a major risk factor for heart disorders, hypertension, diabetes, and stroke [4]. Additionally, obesity is highly associated with decreased life expectancy, cognitive dysfunction, and reduced quality of life [5]. Some studies have reported that patients who are obese have increased need for healthcare utilization than normal-weight patients as a result of medication use and hospital care $[6,7]$.

Depression, which is recognized as a major chronic disease, has become a major health problem worldwide [8]. Depressive disorders make up a relatively significant share $(4.5 \%)$ of the total disability-adjusted life years

(c) The Author(s). 2018 Open Access This article is distributed under the terms of the Creative Commons Attribution 4.0 International License (http://creativecommons.org/licenses/by/4.0/), which permits unrestricted use, distribution, and 
(DALYs) and account for $12.1 \%$ of the total years lived with a disability (YLDs) globally [9]. Depression is a common psychological disorder associated with high morbidity and is a serious economic burden for society in China [10].

The association between obesity and depression has been documented in previous systematic studies $[11,12]$ but remains controversial. Luppino et al. found that obesity at baseline could predict depression onset during follow-up based on a meta-analysis, and the results were most pronounced among Americans; meanwhile, another study reported no robust evidence of this association $[13,14]$. Studies have found that both being underweight and obese have a significant impact on depression, whereas other studies have demonstrated that depressive symptoms are associated with being only underweight or obese $[15,16]$. Moreover, the relationship between obesity and depression may differ by sex. Simon et al. found a stronger relationship between obesity and depression in females based on a cross-sectional study, but Nicole et al. reported that obesity, particularly visceral fat, increased the risk of onset of significant depressive symptoms only in males [11]. Additionally, prospective studies have examined the association between obesity and depression predominantly among children and youth, and a few studies have examined this relationship among older populations $[12,14]$.

In this study, the association between depression and obesity in both sexes was examined among middle-aged and elderly individuals in China using data from the China Health and Retirement Longitudinal Study (CHARLS). Our prior work using the 2013 cross-sectional data (i.e., CHARLS) indicated that the relationship between obesity and depression was negative in males and females [17]. The present study assessed whether the relationship between obesity and depression was still negative in males and females during the follow-up survey and whether changes in obesity had an impact on depression onset over time.

\section{Methods \\ Data}

The data used in this study came from the follow-up survey of the CHARLS targeting the middle-aged and older population (45+) in China. The CHARLS is an ongoing national longitudinal study administered by the National School for Development (China Center for Economic Research), with exams performed every 2 years for a total of 3 waves from 2011 to 2015. The first national baseline survey of the CHARLS was fielded between June 2011 and March 2012 and involved 17,705 respondents who were chosen randomly with a probability proportional to scale (PPS) in 450 villages/resident committees, 150 counties/ districts and 28 provinces. The respondents were interviewed face-to-face in their homes via computer-assisted personal interviewing (CAPI) technology. Physical parameters, such as the respondents' standing height, weight and waist circumference (WC), were measured by the trained investigators with standardized equipment (Index: height; Equipment: SecaTM213 Stadiometer Manufacturer/source: China Seca (Hangzhou) Co., Ltd. Index: weight; Equipment: OmronTMHN-286Scale Manufacturer/source: Krill Technology (Yangzhou) Co., Ltd. Index: waist circumference; Equipment: Soft Tape Measure Manufacturer/source: None.). The medical ethics committee approved the CHARLS study, and all interviewees were required to sign informed consent, Ethics approval for the data collection in CHARLS was obtained from the Biomedical Ethics Review Committee of Peking University (IRB00001052-11015). Ethics approval for the use of CHARLS data was obtained from the University of Newcastle Human Research Ethics Committee (H-2015-0290).

This study used the baseline data from 2011 and follow-up data from 2013 and 2015. To research the association between BMI (WC) and the onset of depression, we limited the samples to respondents who had no depression symptoms in 2011 and had received physical examinations in each of the three surveys. A total of 3337 subjects were included.

\section{Measurements}

This study mainly focused on the association between obesity and depression. Previous studies have identified factors that not only had an impact on this relationship but also on obesity or depression alone, such as activities of daily living (ADLs), chronic disease, smoking and drinking, age, sex, education level, marital status, and Hukou status [1, 2, 13-17]. As a result, these factors were controlled for in this study.

\section{Depression}

Depressive symptoms were assessed using the 10-item Center for Epidemiological Studies Depression Scale (CES-D-10) [18], which has been used to measure depressive symptoms among older adults and was validated among elderly respondents in China [19, 20]. The CES-D10 contains 10 items with 4 response options: 1 ) rarely or none of the time ( $<1$ day); 2 ) some or few times (1-2 days); 3 ) occasionally or a moderate amount of times (3-4 days); and 4) most or all of the time (5-7 days). The values of the 4 options range from 0 to 3 successively. The total score ranges from 0 to 30 , with a lower score indicating a lower level of depressive symptoms. A cutoff score $\geq 10$ was used to identify the respondents who had significant depressive symptoms $[17,18]$.

\section{Obesity}

Body mass index (BMI) and WC were used to define the obesity status of respondents. 
BMI was used to describe general obesity. Respondents were categorized as underweight $\left(<18.5 \mathrm{~kg} / \mathrm{m}^{2}\right)$, normal weight (18.5 to $23.9 \mathrm{~kg} / \mathrm{m}^{2}$ ), overweight ( 24.0 to $\left.27.9 \mathrm{~kg} / \mathrm{m}^{2}\right)$, or obese $\left(\geq 28.0 \mathrm{~kg} / \mathrm{m}^{2}\right)$ based on Chinese criteria [21].

WC was used to describe abdominal obesity. WC $\geq$ $85 \mathrm{~cm}$ in males and $\geq 80 \mathrm{~cm}$ in females was used to define abdominal obesity according to Chinese guidelines [21].

\section{ADL}

ADLs were assessed with the ADL scale [22] using the following series of questions: "Because of a physical, mental, emotional or memory problem, do you have any difficulty with one type of everyday activity, excluding any that you expect to last less than three months?" The everyday activities included dressing, bathing or showering, eating, getting into or out of bed, using the toilet, and controlling urination and defecation. The response scale contained 4 options: 1) No, I don't have any difficulty; 2) I have difficulty but can still do it; 3) Yes, I have difficulty and need help; and 4) I cannot do it. The participants classified as ADL independent had the ability to complete all of the activities without difficulty, whereas those who had difficulty on any item above were regarded as having an ADL disability.

\section{Chronic disease}

Conditions of chronic disease were measured with the following question: "Have you been diagnosed with conditions listed below by a doctor?" The conditions included hypertension; dyslipidemia; diabetes or high blood sugar; cancer or malignant tumors; chronic lung diseases; liver disease; heart problems; stroke; kidney disease; stomach or other digestive disease; emotional, nervous, or psychiatric problems; memory-related disease; arthritis or rheumatism; and asthma. Each condition was assessed by trained investigators separately.

\section{Health behavior}

The habit of smoking was measured with the question "Have you ever chewed tobacco, smoked a pipe, smoked self-rolled tobacco, or smoked cigarettes/cigars", and the possible answers included the following 3 options: 1) Yes; 2) No; or 3) Quit. The habit of drinking was measured with the question "Did you drink any alcoholic beverages, such as beer, wine, or liquor in the past year, and if so, how often?", and the possible answers included the following: 1) Drink more than once a month; 2) Drink but less than once a month; or 3) Do not drink.

\section{Sociodemographic characteristics}

In this study, the sociodemographic characteristics included age, sex, education level, marital status, and Hukou status. Age was divided into two groups including 45 to 59 and 60 or older. Sex was categorized as male or female. Education level was categorized as illiterate, primary school, or junior high school and above. Marital status was categorized as married, cohabitating and divorced, separated, widowed, or never married. Hukou status (Hukou is a centuries-old Chinese word referring to the national household registration that Chinese governments have historically used to try to fix the population in place geographically) was categorized as rural or urban.

\section{Statistics analysis}

Descriptive statistics on individual baseline characteristics were stratified by sex. A chi-squared test was used to compare dichotomous or categorical variables. The relationship between obesity and onset of depression was conducted by survival analysis. The endpoint was defined as the onset of depressive symptoms. In our study, no subjects were lost to follow-up or dropped out, so the subjects with no failure (depression) were censored at the end of the study. Time-dependent Cox proportional hazards models were used to estimate the unadjusted and adjusted hazard ratios (HRs) for the onset of clinically relevant depressive symptoms in relation to time-varying body weight status. Exhibiting depressive symptoms $(1=$ depressive symptoms, $0=$ no depressive symptoms) was a dependent variable. Obesity status (BMI or WC) was a time-dependent independent variable. Age, education level, marital status, Hukou status, chronic disease, ADL, smoking and drinking were also included as control variables in the Cox models. The level of statistical significance was set at 95\% $(P<0.05)$. Associations are presented as the HR with its $95 \%$ confidence interval (CI). Cox models were performed on the total study sample stratified by sex. Statistical analyses were conducted using SAS 9.3.

The general form of the Cox proportional hazards model was:

$$
h(t, X)=h_{0}(t) \exp \left(\beta_{1} x_{1}+\beta_{2} x_{2}+\ldots+\beta_{m} x_{m}\right)
$$

If we introduced intrinsic time-dependent covariates, the general model was converted to: $h(t, X)=h_{0}(t)$ $\exp \left(\beta_{1} x_{1}+\beta_{2} x_{2}+\cdots+\beta_{m} x_{m}(t)\right)$.

where $x_{m}$ is an intrinsic time-dependent covariate whose value changes with time, and $x_{m}(\mathrm{t})$ represents the value of $x_{m}$ at time t. $\beta_{m}$ is the logarithm of the relative risk (HR) for each unit change in $x_{m}$.

\section{Results}

\section{Study population}

The mean age of the participants was $57.78(\mathrm{SD}=8.51)$ years, and $46.63 \%$ of the participants were female. Table 1 presents the baseline characteristics of the study cohort stratified by sex. 
Table 1 Sociodemographic characteristics of the study cohort stratified by sex

\begin{tabular}{|c|c|c|c|c|}
\hline \multirow[t]{2}{*}{ Characteristics } & \multirow{2}{*}{$\begin{array}{l}\text { Total } \\
\text { N (\%) }\end{array}$} & \multirow{2}{*}{$\begin{array}{l}\text { Female } \\
\mathrm{N}(\%)\end{array}$} & \multirow{2}{*}{$\begin{array}{l}\text { Male } \\
\text { N (\%) }\end{array}$} & \multirow[t]{2}{*}{$P$ value } \\
\hline & & & & \\
\hline Total & 3337 & $1556(46.63)$ & $1781(53.37)$ & NA \\
\hline \multicolumn{5}{|l|}{ Demographic } \\
\hline \multicolumn{5}{|l|}{ Age (year) } \\
\hline $45 \sim 59$ & $1985(59.48)$ & $1016(65.30)$ & $969(54.41)$ & \multirow[t]{2}{*}{$<0.001$} \\
\hline$\geq 60$ & $1352(40.52)$ & $540(34.70)$ & $812(45.59)$ & \\
\hline \multicolumn{5}{|l|}{ Marital status } \\
\hline Married/cohabitating & $3100(92.90)$ & $1419(91.20)$ & $1681(94.39)$ & \multirow[t]{2}{*}{$<0.001$} \\
\hline Divorced/separated/widowed/never married & $237(7.10)$ & $137(8.80)$ & $100(5.61)$ & \\
\hline \multicolumn{5}{|l|}{ Socioeconomic status } \\
\hline \multicolumn{5}{|l|}{ Education level } \\
\hline Illiterate & $637(19.09)$ & $467(30.01)$ & $170(9.55)$ & \multirow[t]{3}{*}{$<0.001$} \\
\hline Primary school and below & $1452(43.51)$ & $645(41.45)$ & $807(45.31)$ & \\
\hline Junior high school or above & $1248(37.40)$ & $444(28.53)$ & $804(45.14)$ & \\
\hline \multicolumn{5}{|l|}{ Hukou status (household registration) } \\
\hline Rural & $2699(80.88)$ & $1280(82.26)$ & $1419(79.67)$ & \multirow[t]{2}{*}{0.058} \\
\hline Urban & 638 (19.12) & $276(17.74)$ & $362(20.33)$ & \\
\hline \multicolumn{5}{|l|}{ Health behavior } \\
\hline \multicolumn{5}{|l|}{ Smoking } \\
\hline Yes & $1125(33.71)$ & $74(4.76)$ & $1051(59.01)$ & \multirow[t]{3}{*}{$<0.001$} \\
\hline No & $1932(57.90)$ & $1463(94.02)$ & $469(26.33)$ & \\
\hline Quit & $280(8.39)$ & $19(1.22)$ & $261(14.65)$ & \\
\hline \multicolumn{5}{|l|}{ Drinking } \\
\hline Drink more than once a month & $950(28.47)$ & $91(5.85)$ & $859(48.23)$ & \multirow[t]{3}{*}{$<0.001$} \\
\hline Drink but less than once a month & $184(5.51)$ & $32(2.06)$ & $152(8.53)$ & \\
\hline Do not drink & $2203(66.02)$ & $1433(92.10)$ & $770(43.23)$ & \\
\hline \multicolumn{5}{|l|}{ Health status } \\
\hline \multicolumn{5}{|l|}{ Activity of daily living } \\
\hline Independent & $3100(92.90)$ & $1432(92.03)$ & $1666(93.54)$ & \multirow[t]{2}{*}{0.091} \\
\hline Dependent & $239(7.10)$ & $124(7.97)$ & $115(6.46)$ & \\
\hline \multicolumn{5}{|l|}{ Chronic disease } \\
\hline 0 & $1297(38.87)$ & $604(38.82)$ & $693(38.91)$ & \multirow[t]{3}{*}{0.925} \\
\hline 1 & $1023(30.66)$ & $473(30.40)$ & $550(30.88)$ & \\
\hline$\geq 2$ & $1017(30.48)$ & 479 (30.78) & $538(30.21)$ & \\
\hline General obesity (BMI) & & & & \\
\hline Underweight & $134(4.02)$ & $57(3.66)$ & $77(4.32)$ & $<0.001$ \\
\hline Normal & $1731(51.87)$ & $692(44.47)$ & $1039(58.34)$ & \\
\hline Overweight & $1045(31.32)$ & $545(35.03)$ & $500(28.07)$ & \\
\hline Obese & $427(12.80)$ & $262(16.84)$ & $165(9.26)$ & \\
\hline Abdominal obesity (WC) & & & & \\
\hline Yes & $2025(60.68)$ & $1146(73.65)$ & 879 (49.35) & $<0.001$ \\
\hline No & $1312(39.32)$ & $410(26.35)$ & $902(50.65)$ & \\
\hline
\end{tabular}


The mean age of the enrolled females was 56.41 (SD = 8.46) years. The sample of females in this study was more likely to have a lower education level and to live with a spouse than the enrolled males. The mean age of the males enrolled in the study was $58.98(\mathrm{SD}=8.38$ ) years. The sample of males in this study was older and more likely to drink and smoke than the enrolled females.

In addition, a higher proportion of enrolled females were obese than males according to two different criteria. In terms of general obesity, the proportions of females who were overweight and obese were higher than those of males (overweight: $35.03 \%$ in females, $28.07 \%$ in males; obese: $16.84 \%$ in females, $9.26 \%$ in males). In terms of abdominal obesity, the proportion of obese females was higher than that of males $(73.65 \%$ in females, $49.35 \%$ in males).

\section{Trend of obesity prevalence}

Table 2 shows the changes in the prevalence of obesity at baseline and during both follow-up surveys.

In terms of general obesity, the proportion of overweight females monotonically increased from $35.03 \%$ in 2011 to $37.98 \%$ in 2015. However, compared with $28.07 \%$ in 2011, the proportion of overweight males underwent an instability fluctuation, declining to $29.76 \%$ in 2015 from $30.04 \%$ in 2013. The proportion of obese females also showed an instability fluctuation, increasing from $16.84 \%$

Table 2 Distribution of body mass index and waist circumference categories by survey year and sex for CHARLS participants with no depressive symptoms at baseline

\begin{tabular}{|c|c|c|c|}
\hline & 2011 & 2013 & 2015 \\
\hline \multicolumn{4}{|l|}{ Female } \\
\hline \multicolumn{4}{|c|}{ General obesity (BMI) } \\
\hline Underweight & $57(3.66)$ & $49(3.15)$ & $55(3.53)$ \\
\hline Normal & $692(44.47)$ & $648(41.65)$ & $647(41.58)$ \\
\hline Overweight & $545(35.03)$ & $574(36.89)$ & $591(37.98)$ \\
\hline Obese & $262(16.84)$ & $285(18.31)$ & $263(16.91)$ \\
\hline \multicolumn{4}{|c|}{ Abdominal obesity (WC) } \\
\hline Yes & $1146(73.65)$ & $1264(81.23)$ & $1203(77.31)$ \\
\hline No & $410(26.35)$ & $292(18.77)$ & $353(22.69)$ \\
\hline \multicolumn{4}{|l|}{ Male } \\
\hline \multicolumn{4}{|c|}{ General obesity (BMI) } \\
\hline Underweight & $77(4.32)$ & $74(4.15)$ & $95(5.33)$ \\
\hline Normal & $1039(58.34)$ & $984(55.25)$ & $960(53.90)$ \\
\hline Overweight & $500(28.07)$ & $535(30.04)$ & $530(29.76)$ \\
\hline Obese & $165(9.27)$ & $188(10.56)$ & $196(11.01)$ \\
\hline \multicolumn{4}{|c|}{ Abdominal obesity (WC) } \\
\hline Yes & 879 (49.35) & $1011(56.77)$ & 949 (53.28) \\
\hline No & $902(50.65)$ & $770(43.23)$ & $832(46.72)$ \\
\hline
\end{tabular}

in 2011 to $18.31 \%$ in 2013 and then decreasing to $16.91 \%$ in 2015 . However, the proportion of the male population with obesity monotonically increased from $9.27 \%$ in 2011 to $11.01 \%$ in 2015.

In terms of abdominal obesity, the proportion of the obese population among both males and females underwent an instability fluctuation. This proportion of obese females increased from $73.65 \%$ in 2011 to $81.23 \%$ in 2013 and declined to $77.31 \%$ in 2015 , and the proportion of obese males increased from $49.35 \%$ in 2011 to $56.77 \%$ in 2013 and then decreased to $53.28 \%$ in 2015 .

\section{Onset of depression}

A total of $38.37 \%$ of the enrolled females who did not have depression initially experienced the occurrence of depressive symptoms during the follow-up survey; among males, this rate was $26.67 \%$.

As Table 3 shows, the rates of depression onset decreased monotonically with obesity increases based on BMI, from $29.26 \%$ among normal-weight male participants to $24.00 \%$ among overweight male participants and $16.37 \%$ among male participants with obesity. The rate of depressive symptom onset in males with abdominal obesity based on the WC criteria was lower than that in males without abdominal obesity, from $29.49 \%$ among male participants with obesity to $23.78 \%$ among male participants without obesity.

Additionally, the rates of depressive symptom onset showed no significant association with obesity status in females, even though the association between obesity and depression in females showed a similar trend as that in males using two different criteria.

Association between obesity and the onset of depression Table 4 shows the results of time-dependent Cox proportional hazards models assessing the risk of depressive symptom onset during the follow-up survey according to the obesity status at baseline among participants without depression. Both crude and adjusted HRs for depressive symptom onset decreased as BMI and WC increased in males, but this result was not observed in females. After adjusting for demographic, socioeconomic, health behavioral and health status factors, males with obesity were less likely to suffer from depressive symptoms than normal-weight males according to BMI and WC (BMI: $\mathrm{HR}=0.506,95 \% \mathrm{CI}=0.347-0.736$; WC: $\mathrm{HR}=0.775$, $95 \% \mathrm{CI}=0.644-0.933)$. However, there was no significant association between obesity status and depressive symptom onset according to BMI and WC among females.

\section{Discussion}

In this study, we found that obesity decreased the onset of depression among middle- and older-aged males. However, there was no association between obesity and 
Table 3 Association between obesity and depressive symptom onset by sex based on baseline obesity status

\begin{tabular}{|c|c|c|c|c|c|c|}
\hline \multirow[t]{2}{*}{ Characteristics } & \multicolumn{2}{|l|}{ Female (N (\%)) } & \multirow[t]{2}{*}{$P$ value } & \multicolumn{2}{|l|}{ Male (N (\%)) } & \multirow[t]{2}{*}{$P$ value } \\
\hline & No depressive symptoms & Depressive symptoms & & No depressive symptoms & Depressive symptoms & \\
\hline Total & $959(61.63)$ & $597(38.37)$ & NA & $1306(73.33)$ & $475(26.67)$ & NA \\
\hline \multicolumn{7}{|c|}{ general obesity (BMI) } \\
\hline Underweight & $33(57.89)$ & $24(42.11)$ & 0.899 & $53(68.83)$ & $24(31.17)$ & $<0.01$ \\
\hline Normal & $425(61.41)$ & $267(38.59)$ & & 735 (70.74) & $304(29.26)$ & \\
\hline Overweight & $341(62.56)$ & $204(37.44)$ & & $380(76.00)$ & $120(24.00)$ & \\
\hline Obese & $160(61.06)$ & $102(38.94)$ & & $138(83.63)$ & $27(16.37)$ & \\
\hline \multicolumn{7}{|c|}{ Abdominal obesity (WC) } \\
\hline Yes & $704(61.43)$ & $442(38.57)$ & 0.785 & $670(76.22)$ & 209 (23.78) & $<0.01$ \\
\hline No & $255(62.19)$ & $155(37.81)$ & & $636(70.51)$ & $266(29.49)$ & \\
\hline
\end{tabular}

depression for middle- and older-aged females. This finding again revealed the existence of sex differences in obesity and depression Moreover, regardless of underweight or overweight status, we found that the relationship between weight and depressive symptoms was not significantly different among females and males. The finding of an association between obesity status and depression is consistent with previous epidemiological studies focusing on elderly people [23, 24]. Lawrence et al. examined the association between body weight and depression in 2245 males and females aged 50 to 89 years living in the US, and the results showed that depressive symptoms were inversely associated with body weight in males but not in females [24]. Crisp et al. concluded that there was a significant positive relation between substantial obesity and low levels of depression in males but not in females [25]. Additionally, other studies in China have found that the elderly population with a normal weight is more likely to suffer from depressive symptoms than the obese elderly population $[17,23]$.

A substantial volume of literature has reported an association between obesity and depression. Some studies have reported no association between obesity and depression $[26,27]$, while others have demonstrated that obesity was associated with an increased risk of depression; moreover, some studies have found a positive association in only females [28, 29], and some found have that the association is stronger in females than in males $[13,30]$.

The "jolly fat" hypothesis can be applied to explain the inverse association between obesity and depressive symptom onset [25]. One possible explanation is that food deprivation may lead to depression in people seeking to lose weight through the restriction of diet, although this may occasionally be a protective mechanism against the experience and display of anxiety and depression among people who are obese and experience periodic overeating.

Table 4 HR with 95\% Cl of depression according to the China-specific criteria of obesity based on BMI and WC stratified by sex ${ }^{a}$

\begin{tabular}{|c|c|c|c|c|}
\hline & \multicolumn{2}{|l|}{ Female } & \multicolumn{2}{|l|}{ Male } \\
\hline & Crude HR (95\% Cl) & Adjusted HR (95\% Cl) & Crude HR (95\% Cl) & Adjusted HR $(95 \% \mathrm{Cl})^{\mathrm{b}}$ \\
\hline \multicolumn{5}{|l|}{ Female } \\
\hline \multicolumn{5}{|l|}{ general obesity (BMI) } \\
\hline Normal & 1.000 & 1.000 & 1.000 & 1.000 \\
\hline Underweight & $1.099(0.711 \sim 1.699)$ & $1.089(0.702 \sim 1.689)$ & $1.048(0.702 \sim 1.566)$ & $1.058(0.706 \sim 1.587)$ \\
\hline Overweight & $0.906(0.755 \sim 1.087)$ & $0.879(0.731 \sim 1.057)$ & $0.792(0.643 \sim 0.974)^{*}$ & $0.858(0.693 \sim 1.063)$ \\
\hline Obese & $0.982(0.783 \sim 1.231)$ & $0.906(0.719 \sim 1.141)$ & $0.514(0.355 \sim 0.745)^{* * *}$ & $0.506(0.347 \sim 0.736)^{* * *}$ \\
\hline -2Log likelihood & 8508.942 & 8450.743 & 6953.708 & 6891.256 \\
\hline \multicolumn{5}{|c|}{ Abdominal obesity (WC) } \\
\hline Yes & $0.948(0.778 \sim 1.154)$ & 0.917 (0.752 1.119) & $0.721(0.602 \sim 0.863)^{* *}$ & $0.775(0.644 \sim 0.933)^{* *}$ \\
\hline -2Log likelihood & 8510.231 & 8452.458 & 6958.550 & 6899.773 \\
\hline
\end{tabular}

Note. ${ }^{a}$ Tests for trend were conducted using time-dependent Cox proportional hazards models, treating BMI and WC as categorical and dichotomous variables, respectively

${ }^{\mathrm{b}}$ Adjusted for age, marital status, education level, Hukou status (household registration), smoking, drinking, activities of daily living, and chronic disease ${ }^{*} P<0.05 ;{ }^{*} P<0.01$; and ${ }^{* * *} P<0.001$

$H R$ hazard ratio and $\mathrm{Cl}$ confidence interval 
In addition, overweight males have been shown to be more content than other groups [25].

There is evidence that males are prone to judge a smaller body frame as less preferable than a larger, more muscular body frame. In addition, compared to a heavier body weight, more males regard low body weight as a poor body image. To this end, it is undesirable for men to have progressively lower relative body weights, a view that may be reinforced by societal standards. In fact, males who are in the overweight or obesity category feel more satisfied with their body because of the belief that a large and muscular body size corresponds to the current norms of masculinity [31].

Previous studies have demonstrated a dose-response relationship between obesity and adverse physical health outcomes. Therefore, there may exist a nonlinear relationship between the psychological risks of obesity and obesity. People with obesity are more likely to die at younger ages; thus, due to the survival effect, obese people living through their middle age may have survival genes protecting them from depression [14].

Regarding Chinese people, Chinese traditional culture may also provide other plausible explanations for the "jolly fat" hypothesis. Chinese people are more likely to have positive perceptions of obesity because it is considered good fortune to become fat during middle age in traditional Chinese culture [32].

Meanwhile, the prevalence of central obesity $(73.65 \%$ in females and $49.35 \%$ in males) in our study differed from that reported in other studies from China. One possible reason for this difference is that the other studies used a more stringent criteria of WC $(\geq 90 \mathrm{~cm}$ in males and $\geq 85 \mathrm{~cm}$ in females) [33]. Another reason is that the study sample did not exhibit depressive symptoms at baseline, and as we have found that there is a negative association between obesity and depression, it is reasonable that the prevalence of obesity was higher among our cohort than among that of other studies.

BMI has been proven to be a cheap, convenient and common tool to screen overweight and obesity. However, BMI measures are limited because they do not discriminate between fat and lean mass. Thus, the prevalence of obesity defined by excess body fat, particularly in overweight individuals, may be underestimated using BMI [34]. Both general and abdominal obesity assessments are important and necessary to improve the evaluation of potential health risks and to provide an accurate prognosis by estimating fat distribution. It is reported that people at risk tend to store their excess weight abdominally; thus, measurements of WC may help improve their treatment [35]. In this study, we used both general obesity (BMI) and abdominal obesity (WC) to examine the relationship between obesity and depression, and we found that the WC showed equivalent results to BMI. We also observed a significant relationship between obesity and depression in males but not in females. Therefore, in assessing patients with depression risk associated with obesity, measuring WC could be an alternative choice to measuring BMI.

Even though the association between obesity and depression in females was not statistically significant, this finding is consistent with that of previous epidemiological studies focusing on elderly people, as mentioned above. Nevertheless, we found that the prevalence of obesity and depression among females was higher than that among males, which is also consistent with the published literature [36, 37]. Owing to dietary patterns, females have a higher risk of obesity/central obesity than males [38]. In addition, females are more likely to be depressed than males because of hormonal fluctuations, such as undue sensitivity and hormonal changes during menopause [17].

Several limitations of this study should be noted. First, the CES-D-10 was used to examine the number of selfreported depressive symptoms during the past week, which could have introduced recall bias. However, the CES-D-10 is a commonly used tool to evaluate clinically significant depressive symptoms. Second, the severity of depression could not be calculated, which may have introduced bias, as the association between obesity and depression may be stronger among participants who are more depressed. Third, this article adopted the Chinese criteria of obesity status; as a result, the results of this research cannot be generalized to other ethnic groups.

\section{Conclusion}

In conclusion, obesity is more likely to be associated with the onset of depression in males than in females. Additionally, measuring $\mathrm{WC}$ could be an alternative to measuring BMI when examining the association between obesity and depression. The impact of the association between obesity status and depression seems to be of sufficient importance to encourage health care providers to monitor mood status among people who are seen as needing weight loss; thus, providers should take into consideration mental changes and the rapid loss of weight.

\section{Abbreviation}

HS: Hukou status

\section{Acknowledgements \\ We are grateful to the China Center for Economic Research at Beijing University for providing us with the data, and we thank the CHARLS research and field team for collecting the data.}

\section{Availability of data and materials}

The dataset collected and analyzed in the current study are available from the corresponding author on reasonable request.

\section{Ethical standards}

The experiments complied with the current laws of the country in which they were performed. 


\section{Experimental subjects/animals}

The experimental protocols were approved by the appropriate institutional review committee and met the guidelines of their responsible governmental agency.

\section{Authors' contributions}

$\mathrm{HL}$ designed the study, performed the experiments, analyzed the data, and wrote the manuscript; $J \mathrm{~L}$ analyzed the data; QZ prepared the manuscript; PC analyzed the data; XR helped perform the analyses, participated in constructive discussions and contributed to the conception of the study; AF performed the experiments; HL performed the experiments; and LL performed the experiments. All authors read and approved the final manuscript.

\section{Ethics approval and consent to participate}

Ethics approval for the study was granted by the Ethics Review Committee of Peking University, and all the participants provided signed informed consent at the time of participation. The study methodology was carried out in accordance with approved guidelines.

\section{Consent for publication}

Not applicable.

\section{Competing interest}

The authors declare that there are no conflicts of interest.

\section{Publisher's Note}

Springer Nature remains neutral with regard to jurisdictional claims in published maps and institutional affiliations.

\section{Author details \\ 'West China School of Public Health (No. 4 West China Teaching Hospital), Sichuan University, Chengdu 610041, Sichuan, China. ${ }^{2}$ Department of Medical Records, West China Secondary University Hospital, Sichuan University, Chengdu 610041, Sichuan, China. ${ }^{3}$ Department of Health Industry, Health and Family Planning Bureau of Wuhou District, Chengdu 610041, Sichuan, China. ${ }^{4}$ Department of Health Related Social and Behavioral Science, West China School of Public Health (No. 4 West China Teaching Hospital), Sichuan University, No. 17 Section 3, Renmin South Road, Chengdu 610041 Sichuan, China.}

Received: 9 January 2018 Accepted: 11 July 2018

Published online: 24 July 2018

\section{References}

1. Ha H, Han C, Kim B. Can obesity cause depression? A pseudo-panel analysis. J Prev Med Public Health. 2017:50:262-7.

2. Vogelzangs N, Kritchevsky SB, Beekman AT, Brenes GA, Newman AB, Satterfield S, Yaffe K, Harris TB, Penninx BW. Health ABC Study, Obesity and onset of significant depressive symptoms: results from a prospective community-based cohort study of older men and women. J Clin Psychiatry. 2010;71:391-9.

3. Pagan $\mathrm{R}$, de Haro CO, Sánchez CR. Obesity, job satisfaction and disability at older ages in Europe. Econ Hum Biol. 2016;20:42-54.

4. Cao ZK, Huang Y, Yu HJ, Yuan S, Tang BW, Li QX, Li XT, Yang XH, He QQ. Association between obesity phenotypes and incident hypertension among Chinese adults: a prospective cohort study. Public Health. 2017;149:65-70.

5. Chan JS, Yan JH, Payne VG. The impact of obesity and exercise on cognitive aging. Front Aging Neurosci. 2013;5:97.

6. Yach D, Stuckler D, Brownell KD. Epidemiologic and economic consequences of the global epidemics of obesity and diabetes. Nat Med. 2006:12:62-6.

7. Shamseddeen H, Getty JZ, Hamdallah IN, Ali MR. Epidemiology and economic impact of obesity and type 2 diabetes. Surg Clin North Am. 2011; 91:1163-72. vil

8. de Winter CF, Bastiaanse LP, Hilgenkamp TI, Evenhuis HM, Echteld MA. Overweight and obesity in older people with intellectual disability. Res Dev Disabil. 2012;33:398-405.

9. Ustün TB, Ayuso-Mateos JL, Chatterii S, Mathers C, Murray CJ. Global burden of depressive disorders in the year 2000. Br J Psychiatry. 2004;184:386-92.
10. Zhou X, Li J, Gu W, Wang J, Zhu Y, Zhang G, Ding Y, Tang Y. Prevalence and associated factors of anxiety and depression among patients with chronic respiratory diseases in eight general hospitals in Jiangsu Province of China: a cross-sectional study. Psychiatry Res. 2017;251:48-53.

11. Jantaratnotai N, Mosikanon K, Lee Y, McIntyre RS. The interface of depression and obesity. Obes Res Clin Pract. 2017;11:1-10.

12. Lazarevich I, Irigoyen Camacho ME, Velázquez-Alva MDC, Zepeda Zepeda M. Relationship among obesity, depression, and emotional eating in young adults. Appetite. 2016;107:639-44.

13. Luppino FS, de Wit LM, Bouvy PF, Stijnen T, Cuijpers P, Penninx BW, Zitman FG. Overweight, obesity, and depression: a systematic review and metaanalysis of longitudinal studies. Arch Gen Psychiatry. 2010;67:220-9.

14. Xiang X, An R. Obesity and onset of depression among U.S. middle-aged and older adults. J Psychosom Res. 2015;78:242-8.

15. Kim J, Noh JW, Park J, Kwon YD. Body mass index and depressive symptoms in older adults: a cross-lagged panel analysis. PLoS One. 2014;9:e1 14891.

16. de Wit LM, van Straten A, van Herten M, Penninx BW, Cuijpers P. Depression and body mass index, a u-shaped association. BMC Public Health. 2009;9:14.

17. Qian J, Li N, Ren X. Obesity and depressive symptoms among Chinese people aged 45 and over. Sci Rep. 2017;7:45637.

18. Andresen EM, Malmgren JA, Carter WB, Patrick DL. Screening for depression in well older adults: evaluation of a short form of the CES-D (Center for Epidemiologic Studies Depression Scale). Am J Prev Med. 1994;10:77-84.

19. Boey KW. Cross-validation of a short form of the CES-D in Chinese elderly. Int J Geriatr Psychiatry. 1999;14:608-17.

20. Cheng HG, Chen S, McBride O, Phillips MR. Prospective relationship of depressive symptoms, drinking, and tobacco smoking among middle-aged and elderly community-dwelling adults: results from the China health and retirement longitudinal study (CHARLS). J Affect Disord. 2016;195:136-43.

21. McNatty KP, Hudson NL, Collins F, Fisher M, Health DA, Henderson KM. Effects of oestradiol-17 beta, progesterone or bovine follicular fluid on the plasma concentrations of FSH and LH in ovariectomized Booroola ewes which were homozygous carriers or non-carriers of a fecundity gene. J Soc Reprod Fertil. 1989;87:573-85.

22. Katz S, Ford AB, Heiple KG, Newill VA. Studies of illness in the aged: recovery after fracture of the hip. J Gerontol. 1964;19:285-93.

23. Ho RC, Niti M, Kua EH, Ng TP. Body mass index, waist circumference, waisthip ratio and depressive symptoms in Chinese elderly: a population-based study. Int J Geriatr Psychiatry. 2008;23:401-8.

24. Palinkas LA, Wingard DL, Barrett-Connor E. Depressive symptoms in overweight and obese older adults: a test of the "jolly fat" hypothesis. J Psychosom Res. 1996;40:59-66.

25. Crisp AH, McGuiness B. Jolly fat: relation between obesity and psychoneurosis in general population. Br Med J. 1976;1:7-9.

26. Faith MS, Matz PE, Jorge MA. Obesity-depression associations in the population. J Psychosom Res. 2002;53:935-42.

27. Roberts RE, Duong HT. Does major depression affect risk for adolescent obesity? J Affect Disord. 2015;186:162-7.

28. Simon GE, Ludman EJ, Linde JA, Operskalski BH, Ichikawa L, Rohde P, Finch EA, Jeffery RW. Association between obesity and depression in middle-aged women. Gen Hosp Psychiatry. 2008;30:32-9.

29. Blümel JE, Fica J, Chedraui P, Mezones-Holguín E, Zuñiga MC, Witis S, Vallejo MS, Tserotas K, Sánchez H, Onatra W, Ojeda E, Mostajo D, Monterrosa A, Lima S, Martino M, Hernández-Bueno JA, Gómez G, Espinoza MT, Flores D, Calle A, Bravo LM, Benítez Z, Bencosme A, Barón G, Aedo S. Collaborative Group for Research of the climacteric in Latin America, sedentary lifestyle in middle-aged women is associated with severe menopausal symptoms and obesity. Menopause. 2016;23:488-93.

30. Mannan M, Mamun A, Doi S, Clavarino A. Is there a bi-directional relationship between depression and obesity among adult men and women? Systematic review and bias-adjusted meta analysis. Asian J Psychiatry. 2016;21:51-66.

31. McCabe MP, McGreevy SJ. Role of media and peers on body change strategies among adult men: is body size important? Eur Eat Disord Rev. 2011;19:438-46.

32. Li ZB, Ho SY, Chan WM, Ho KS, Li MP, Leung GM, Lam TH. Obesity and depressive symptoms in Chinese elderly. Int J Geriatr Psychiatry. 2004;19:68-74.

33. Zhu J, Gao R, Zhao S, Lu G, Zhao D, Li J. Guidelines for prevention and treatment of dyslipidemia in Chinese adults (2016 revision). Chin Circul J. 2016;10:937-53.

34. Romero-Corral A, Somers VK, Sierra-Johnson J, Thomas RJ, Collazo-Clavell ML, Korinek J, Allison TG, Batsis JA, Sert-Kuniyoshi FH, Lopez-Jimenez F. Accuracy of body mass index in diagnosing obesity in the adult general population. Int J Obes. 2008;32:959-66. 
35. Després JP, Lemieux I, Prud'Homme D. Treatment of obesity: need to focus on high risk abdominally obese patients. BMJ. 2001;322:716-20.

36. Mi YJ, Zhang B, Wang HJ, Yan J, Han W, Zhao J, Liu DW, Tian QB. Prevalence and secular trends in obesity among Chinese adults, 1991-2011. Am J Prev Med. 2015;49:661-9.

37. Qin X, Zhang Y, Cai Y, He M, Sun L, Fu J, Li J, Wang B, Xing H, Tang G, Wang X, Xu X, Xu X, Huo Y. Prevalence of obesity, abdominal obesity and associated factors in hypertensive adults aged $45-75$ years. Clin Nutr. 2013; 32:361-7.

38. Shi Z, Hu X, Yuan B, Hu G, Pan X, Dai Y, Byles JE, Holmboe-Ottesen G. Vegetable-rich food pattern is related to obesity in China. Int J Obes. 2008: 32:975-84.

Ready to submit your research? Choose BMC and benefit from:

- fast, convenient online submission

- thorough peer review by experienced researchers in your field

- rapid publication on acceptance

- support for research data, including large and complex data types

- gold Open Access which fosters wider collaboration and increased citations

- maximum visibility for your research: over $100 \mathrm{M}$ website views per year

At BMC, research is always in progress.

Learn more biomedcentral.com/submissions 